\title{
A Key Enzyme of the Leloir Pathway Is Involved in Pathogenicity of Leptosphaeria maculans Toward Oilseed Rape
}

\author{
E. Remy, ${ }^{1}$ M. Meyer, ${ }^{1}$ F. Blaise,${ }^{1}$ U. K. Simon, ${ }^{2}$ D. Kuhn, ${ }^{3}$ M. H. Balesdent, ${ }^{1}$ and T. Rouxel ${ }^{1}$ \\ ${ }^{1}$ INRA, UMR 1290 BIOGER, Route de Saint-Cyr, F-78026 Versailles cedex, France; ${ }^{2}$ Institute for Plant Sciences, \\ Dept. Plant Physiology, Karl-Franzens-University Graz, Schubertstr. 51, 8010 Graz, Austria; ${ }^{3}$ Lehrstuhl Spezielle Botanik \\ und Mykologie, Universität Tübingen, Auf der Morgenstelle 1, 72076 Tübingen, Germany
}

Submitted 23 September 2008. Accepted 10 February 2009.

Agrobacterium tumefaciens-mediated random insertional mutagenesis was used to investigate pathogenicity determinants in Leptosphaeria maculans. One tagged nonpathogenic mutant, termed $\mathbf{m} 186$, is analyzed in detail here. Microscopic analyses of infected plant tissues revealed that m186 is specifically blocked at the invasive growth phase after an unaffected initial penetration stage and is unable to switch to the necrotrophic lifestyle. In addition, m186 exhibits an altered cell wall and seems to be affected in its ability to produce cell-wall-degrading enzymes. The T-DNA insertion occurs in the intergenic region between two headto-tail genes, leading to a constitutive upregulation of their expression. Complementation experiments showed that only one of these two genes, Lmepi, fully accounts for the mutant phenotype. Bioinformatics and expression analyses along with functional studies suggested that the Lmepi gene encodes for the highly conserved UDP-glucose-4-epimerase, a key enzyme of the Leloir pathway involved in galactose metabolism. For the third time, this study highlights the intimate connection between primary metabolism and pathogenicity in L. maculans. This finding, along with similar data obtained from the related species Stagonospora nodorum, indicates the importance of in planta nutrition for the success of infection of plants by fungi belonging to class Dothideomycete.

Fungal pathogens of plants must adapt to large variations in environmental conditions in order to successfully infect their host and complete their life cycle. In particular, nutrient availability is one of the key signals that trigger both pathogenicity gene expression and metabolic adjustments during the pathogen life's cycle (Divon and Fluhr 2007). Traditionally, fungal plant pathogens are classified according to their nutrition lifestyle in planta. Necrotrophs do not possess specialized feeding structures and derive nutrients from sacrificed cells. Biotrophic pathogens depend on the host for their entire life cycle and derive nutrients from living cells by differentiating specialized feeding structures (e.g., haustoria) (Perfect and Green 2001).

Corresponding author: T. Rouxel; Telephone: +33 1308332 29; Fax: +33 1308331 95; E-mail: rouxel@ versailles.inra.fr.

Nucleotide sequence data is available in GenBank database under accession numbers AM941451 (Lmsad1) and AM941452 (Lmepi).

* The $\boldsymbol{e}$-Xtra logo stands for "electronic extra" and indicates that a supplemental figure is published online.
The term "hemibiotrophic" distinguishes those pathogens which maintain host cells alive until establishment within the host before switching to a necrotrophic lifestyle and, in some cases, reestablishment of an endophytic nondestructive lifestyle (Perfect and Green 2001; Rouxel and Balesdent 2005). When dealing with foliar pathogens, the infection process itself involves three distinct developmental stages (i.e., germination on and penetration of the host surface, proliferation in host tissues, and sporulation). At each stage, the fungus is faced with nutritional changes (Solomon et al. 2003). In the absence of nutrient availability on the plant surface, the first stage relies on the catabolism of internal stores whereas, once inside the plant tissues, the fungus establishes mobilization mechanisms that ensure adequate uptake of host-derived metabolites for proliferation (Divon and Fluhr 2007). When these abundant nutrient sources are exhausted, the fungus then completes its life cycle by sporulating (Solomon et al. 2005a).

Thus, primary metabolism plays a crucial role during the infection process, with several key metabolic pathways required for pathogenicity of various fungal plant pathogens according to their particular infection strategies and host nutrient accessibility (Solomon et al. 2003). Lipids are the main storage carbohydrates in fungal spores and, recently, lipid catabolism has emerged as essential for infection processes, especially during penetration. In Magnaporthe grisea, the enormous turgor pressure generated in appressoria is a consequence of the accumulation in the cell of very large amounts of glycerol, which is synthesized predominantly via triacylglycerol lipase activity using lipid reserves mobilized from the conidium (Thines et al. 2000). The fatty acids generated by the lipolysis are converted in acetyl-CoA via $\beta$-oxidation, whose role in appressorial functionality has been demonstrated by deletion of PEX6 orthologues in M. grisea and Colletotrichum lagenarium. However, $\beta$-oxidation is not involved in invasive growth in these two pathogens (Asakura et al. 2006; Ramos-Pamplona and Nagvi 2006). In Ustilago maydis, in contrast, deletion of $M F E 2$, which encodes a multifunctional enzyme that catalyzes the second and third reactions in $\beta$-oxidation of fatty acids, blocks extensive proliferation of mycelia in planta (Klose and Kronstad 2006). Acetyl-CoA is further assimilated via the glyoxylate cycle, whose fungal mutants in the two principal enzymes, isocitrate lyase (ICL) and malate synthase (MLS), are unable to grow on fatty acids as sole carbon source (Idnurm and Howlett 2002; Solomon et al. 2004a; Wang et al. 2003). In $M$. grisea, the absence of the ICL1 gene delays appressorium maturation and penetration hyphae development but is dispensable for proliferation during the necrotrophic stage (Wang et 
al. 2003). Inversely, the icll mutant of Leptosphaeria maculans and the mls mutant of Stagonospora nodorum exhibit both a low rate of germination and a defect in invasive growth (Idnurm and Howlett 2002; Solomon et al. 2004a). All these findings indicate a conserved role for lipid metabolism in fungal phytopathogens regardless of their pathogenic lifestyle but in respect with their infection strategy.

The implication of the PEX6 gene in $\beta$-oxidation and pathogenicity of $M$. grisea has been shown by a Agrobacterium tumefaciens-mediated random insertional mutagenesis (ATMT) approach (Ramos-Pamplona and Nagvi 2006). The use of random ATMT to discover novel pathogenicity factors in fungal phytopathogens generates an ever-growing amount of data (Elliott and Howlett 2006; Gupta and Chattoo 2007; Odenbach et al. 2007; Ramos-Pamplona and Nagvi 2006; Remy et al. $2008 \mathrm{a}$ and b). Using this strategy, three of these novel factors have been identified in the stem canker of crucifers agent, $L$. maculans, and, surprisingly, all are involved in basic cellular processes, such as in $\beta$-oxidation (THIOL), GPI anchor biosynthesis (LmGPI15), or intracellular $\mathrm{pH}$ homeostasis (LmPMA1) (Elliott and Howlett 2006; Remy et al. 2008a and b). Despite these significant advances, molecular events underlying $L$. maculans pathogenicity are still largely unknown (Rouxel and Balesdent 2005).

Following the identification of approximately $3.8 \%$ of $L$. maculans ATMT transformants affected in their pathogenicity (Blaise et al. 2007), we focused here on the characterization of one of the nonpathogenic mutants, m186, which was previously demonstrated to be tagged (Blaise et al. 2007). This mutant exhibited an altered proliferation into host tissues after an unaffected penetration stage. Ultrastructural studies further revealed that m186 was unable to degrade host cell wall and thus to switch to the necrotrophic lifestyle. The T-DNA integration occurred in the intergenic region between two head-to-tail genes, leading to a constitutive upregulation of their expression. Complementation experiments further identified one of the two genes as responsible for the mutant phenotype. The corresponding gene is predicted to encode an UDP-glucose-4epimerase, the fourth enzyme of the Leloir pathway, involved in galactose metabolism. Expression and functional analyses were performed, and putative roles played by this enzyme during the L. maculans infection cycle are discussed.

\section{RESULTS}

The mutant $\mathbf{m} 186$ is blocked at the invasive growth stage.

The mutant m186 was previously shown to be significantly and reproducibly affected in its ability to cause disease on cotyledons of oilseed rape (Blaise et al. 2007). The mutant induced a dark necrotic lesion which can extend from the site of wounding, but to a much lesser extent than the wild-type (WT) isolate. Symptoms never evolved to resemble the typical cotyledon symptoms whatever the scoring date. However, m186 was able to produce pycnidia at the surface of the lesion (Fig. 1A). Comparison between WT and mutant isolates constitutively expressing the green fluorescent protein (GFP) showed that m186 was able to germinate on the plant surface and to penetrate the plant tissues at the point of wounding, as the WT isolate could do (Fig. 1C). Cytological examination of trypan-blue-stained cotyledons at different stages after inoculation allowed us to detect m186 hyphae in intercellular spaces of collapsed or apparently healthy plant tissues but to a lesser density than those of the WT isolate. The latter showed an extensive colonization of intercellular spaces away from the initial inoculation point (Fig. 1B). These results indicated that m186 was specifically blocked at the invasive growth stage of the infection process at the cotyledon level, following an unaf- fected initial penetration stage. The final stage of the disease, stem necrosis, was assessed macroscopically and showed that m186 was able to colonize the stem tissues significantly less consistently than the WT isolate (Fig. 1D). No significant effect of the mutation on either germination, sporulation, mating, or growth was observed when m186 was grown in vitro on different agar media (data not shown). In addition, the T-DNA insertion did not cause observable effects on mycelial morphology at the macroscopic or microscopic levels (data not shown).

\section{T-DNA is inserted}

in the intergenic region of two head-to-tail genes.

Genetic and Southern blotting analyses previously showed that the m186 phenotype cosegregated with the presence of a unique insertion of the T-DNA (Blaise et al. 2007). Thermal asymmetric interlaced polymerase chain reaction (TAIL-PCR) experiments allowed us to recover the genomic sequence flanking the left border of the T-DNA as a 383-bp sequence. Five positive BAC clones were obtained following the PCRscreening of the 7x v23.1.3 partial HindIII BAC library (Gout et al. 2006), of which one was chosen for subsequent subcloning into pUC18. An 11.8-kb EcoRV fragment encompassing the T-DNA integration site was fully sequenced. The T-DNA integration led to the deletion of $24 \mathrm{bp}$ of the right T-DNA border and $21 \mathrm{bp}$ of the genomic sequence at the right side of the integration, without any rearrangement of either the left TDNA border or the genomic sequence at the left side of the integration (data not shown).

FGENESH predicted the occurrence of six putative open reading frames (ORF) (orf1, orf2, orf3, orf4, orf5, and orf6) in the genomic region (Fig. 2). The two closest ORF from the insertion site, orf4 and orf5, were in a head-to-tail orientation and were experimentally annotated for $5^{\prime}$ and $3^{\prime}$ untranslated regions (UTR) and for presence of introns. A large intergenic region of 2,432 nucleotides separated their initiation codons, from which the insertion event of the T-DNA occurred 1,762 and 649 bp upstream of orf4 and orf5, respectively (Fig. 2). Experimental annotation of the 5' UTR and sequencing of the corresponding transcripts in m186 further revealed that both transcripts were identical in m186 and WT isolates, which did not allow us to resolve which gene was implicated in m186 phenotype (data not shown).

Proteins potentially encoded by orf 2 , orf 3 , and orf6 were highly conserved in eukaryotes, with orf 2 encoding a putative ubiquitin carboxyl-terminal hydrolase, orf3 encoding a putative cofactor for methionyl- and glutamyl-tRNA synthetases, and orf6 encoding a putative homologue of the DNA replication licensing factor MCM6. The predicted protein ORF4 exhibited very high homology with UDP-glucose-4-epimerase of various eukaryotes. In contrast, only the carboxyl-terminal part of the predicted protein ORF5 exhibited moderate similarity with the same part of a putative protein of various Ascomycetes, as well as with the entire Sad1 protein of Schizosaccharomyces pombe (Hagan and Yanagida 1995). Accordingly, we named the orf4 gene Lmepi and the orf5 gene Lmsadl. The highest degrees of homology were found in all cases with corresponding putative proteins of the closely related species $S$. nodorum (Fig. 2). Gene organization was also identical in the two species, although intergenic regions were generally smaller in S. nodorum than in L. maculans (Fig. 2).

\section{The T-DNA insertion leads}

to the overexpression of Lmsad1 and Lmepi.

The gene expression level of Lmsadl and Lmepi was measured by quantitative reverse-transcription (RT)-PCR relative to that of $\beta$-tubulin, using actin as an internal control (Fudal et al. 
2007) (Fig. 3A). In the WT isolate, both Lmsadl and Lmepi were constitutively expressed in vitro. The genes were 150 and 75 times, respectively, less expressed than actin in mycelium or in conidia germinating either in complete or minimum medium (Fig. 3A). Following plant inoculation, Lmsadl expression was increased by 10 -fold at 3 days postinoculation (dpi) and then increased by 20 -fold at 6 dpi. Expression then slowly decreased after 6 dpi to reach a level comparable with that of the in vitro expression at $12 \mathrm{dpi}$ (Fig. 3A). Expression of Lmepi was similar with a lesser induction (i.e., a twofold increase at $3 \mathrm{dpi}$ and a sevenfold increase at $6 \mathrm{dpi}$ ). Expression then decreased after 6 dpi as observed for Lmsadl but remained at a level higher than in vitro at least until 12 dpi (Fig. 3A). Although Lmsadl and Lmepi expression levels were slightly different one from the other, expression profiles of the two genes were very similar, suggesting a co-regulation of the expression of the two genes.
Gene expression analyses in m186 revealed an increased expression of both genes compared with the WT isolate in all in vitro conditions tested, with a 1.5 to 2 times increase for Lmsadl and a 3 to 5 times increase for Lmepi, depending on the condition (Fig. 3A). Similarly, the two genes were expressed more highly than in the WT isolate during plant infection. In addition, Lmsadl and Lmepi expression did not decrease at 9 and $12 \mathrm{dpi}$, thus contrasting with what was observed in the WT isolate (Fig. 3A). All these data suggested that the T-DNA integration led to a partial deregulation of Lmsadl and Lmepi expression during both in vitro and in planta conditions, which resulted in a constitutive overexpression of the two genes.

\section{Complementation of $\mathbf{m 1 8 6}$}

by Lmepi but not Lmsad1 restores pathogenicity.

Functional complementation experiments were performed by transforming m186 with two different complementation
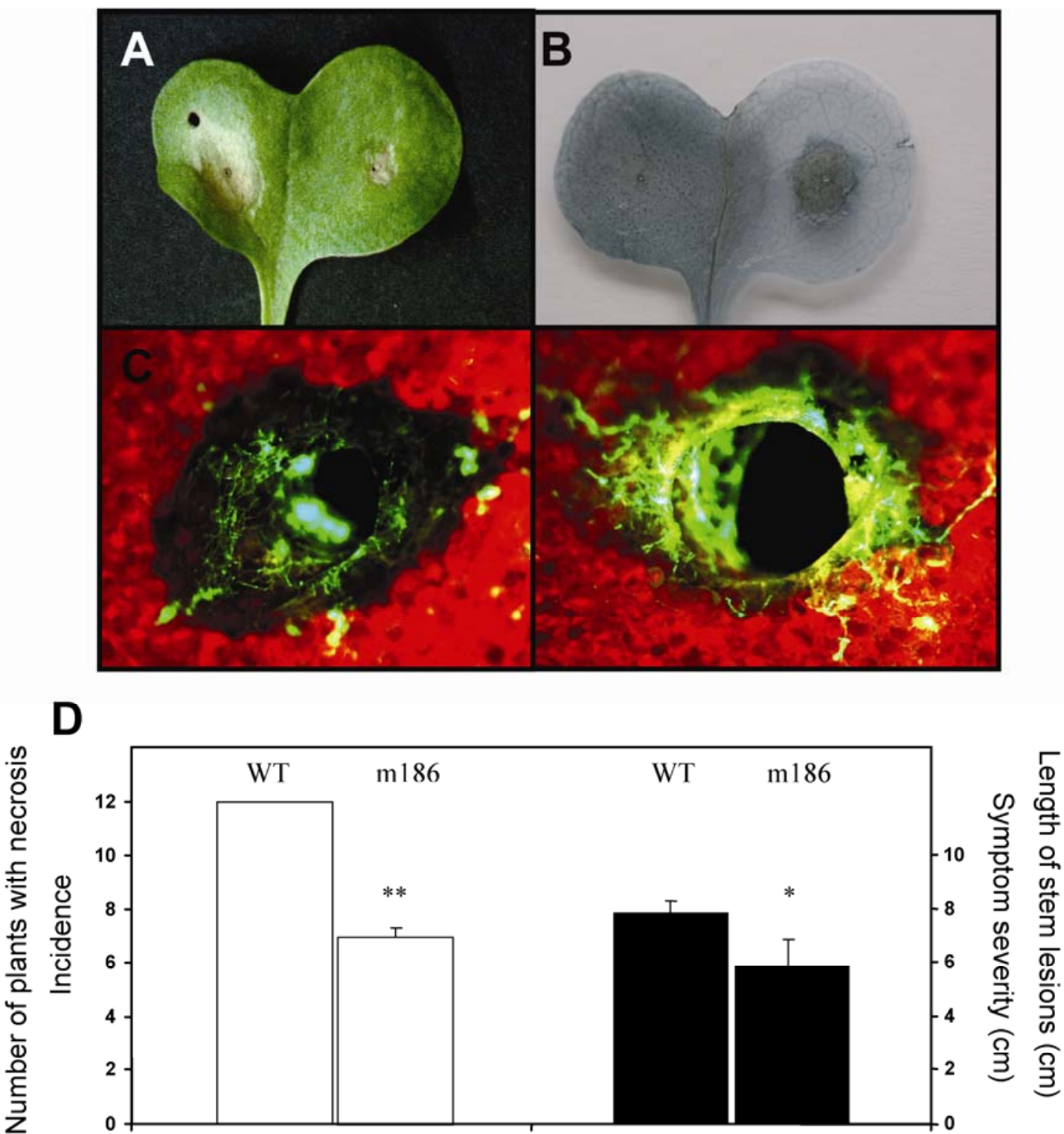

Fig. 1. Pathogenicity behavior of the Leptosphaeria maculans mutant $\mathrm{m} 186$ isolate on Brassica napus. A, Cotyledons of B. napus cv. Westar were inoculated with the wild-type (WT) isolate (left part) and m186 (right part). Photographs were taken 21 days after inoculation. B, Trypan blue-staining of A. C, Cotyledons of B. napus cv. Westar were inoculated with the near-isogenic isolate v41.4.6 (fifth backcross) of the WT isolate transformed by a green fluorescent protein (GFP) strongly expressing construct (left part) and with the m186GFPa isolate (right part). Photographs were taken 3 days after inoculation. D, Stems of B. napus cv. Westar were inoculated with the WT and m186 isolates. Symptoms were scored 3 months after inoculation. Incidence (number of plants infected) and symptom severity $(\mathrm{cm})$ are indicated by white and black bars, respectively. Student's test values were calculated between the WT and $\mathrm{m} 186$ isolates. Probability: * and ** indicate $P=0.05$ and 0.001 , respectively. 
constructs, each corresponding to the entire intergenic region in addition to either Lmsadl or Lmepi genes. In all, 14 and 15 complemented isolates were recovered for Lmsadl and Lmepi transformation experiments, respectively, and PCR analyses indicated that all the integration sites maintained the initial $\mathrm{T}$ DNA insertion and, thus, were ectopic (data not shown). Pathogenicity assessment revealed that only isolates complemented with Lmepi recovered the ability to induce WT symptoms on oilseed rape cotyledons and stems (Table 1). In contrast, isolates transformed with Lmsadl induced a necrotic lesion similar to that induced by $\mathrm{m} 186$ on cotyledons and exhibited a reduced capacity to colonize the stems (Table 1). Expression level of Lmepi and Lmsadl were analyzed in planta for three complemented isolates each (Fig. 3B). Compared with the WT isolate, all the complemented isolates showed an increase in Lmepi or Lmsadl expression levels, respectively (Fig. 3B). In addition, the in planta increase in expression, although variable among the complemented isolates, was significantly higher than the one detected in m186 (Fig. 3B). These data demonstrated that deregulated expression of Lmepi but not Lmsadl accounted for the m186 loss of pathogenicity phenotype.

\section{The Lmepi gene encodes}

a putative UDP-glucose-4-epimerase.

The Lmepi gene possessed no intron and encoded a 374amino-acid putative protein with a predicted molecular mass of $41.4 \mathrm{kDa}$. Hydropathy analysis did not reveal the presence of potential membrane-spanning regions (Kyte and Doolittle 1982). Furthermore, the putative LmEPI protein was predicted to be cytoplasmic, like the other eukaryotic UDP-glucose-4epimerases. Indeed, the putative LmEPI protein showed strong homology with UDP-glucose-4-epimerases from filamentous fungi, with, for instance, $73 \%$ amino acid identity with that of M. grisea and $68 \%$ identity with that of Gibberella zeae (Supplementary Fig. S1). Sequence conservation was also very high with UDP-glucose-4-epimerases from yeast, human, plant, and bacteria, with an average $45 \%$ identity. In addition, the putative LmEPI protein possessed all residues found to be functionally relevant in the yeast epimerase domain of GAL10 and the conserved Tyr-X-X-X-Lys motif involved in catalysis activity (Holden et al. 2003).

UDP-glucose-4-epimerase catalyzes the interconversion of UDP-galactose and UDP-glucose (Frey 1996; Holden et al. 2003). Therefore, we evaluated the ability of m186 to grow on these two carbon sources (Fig. 4A). Galactose appeared to be a favorable source of carbon for m186, because it grew significantly better than the WT isolate. In addition, m186 was less able to use glucose as the sole carbon source, because its growth was significantly reduced compared with the WT isolate and compared with biomass production in galactose-containing medium (Fig. 4A). We also examined the sensitivity and relative alteration of growth of the WT isolate and $\mathrm{m} 186$ in the presence of cell-wall-perturbating agents (Table 2). The mutant exhibited a strong sensitivity to compounds that interfere in the cross-linking of cell wall components, with a reduction of approximately 50 and $40 \%$ for Congo red and sodium dodecyl sulfate (SDS), respectively. The inhibitory effect was significantly more severe than for the WT isolate (Table 2).

\section{Lmepi gene expression is induced by galactose.}

Bioinformatics analysis of the 2,432 bp of upstream promoter sequence of Lmepi revealed the presence of potential regulatory elements (data not shown). These included one putative binding site for the zinc-finger protein Mig1 and one putative consensus

\section{L. maculans}

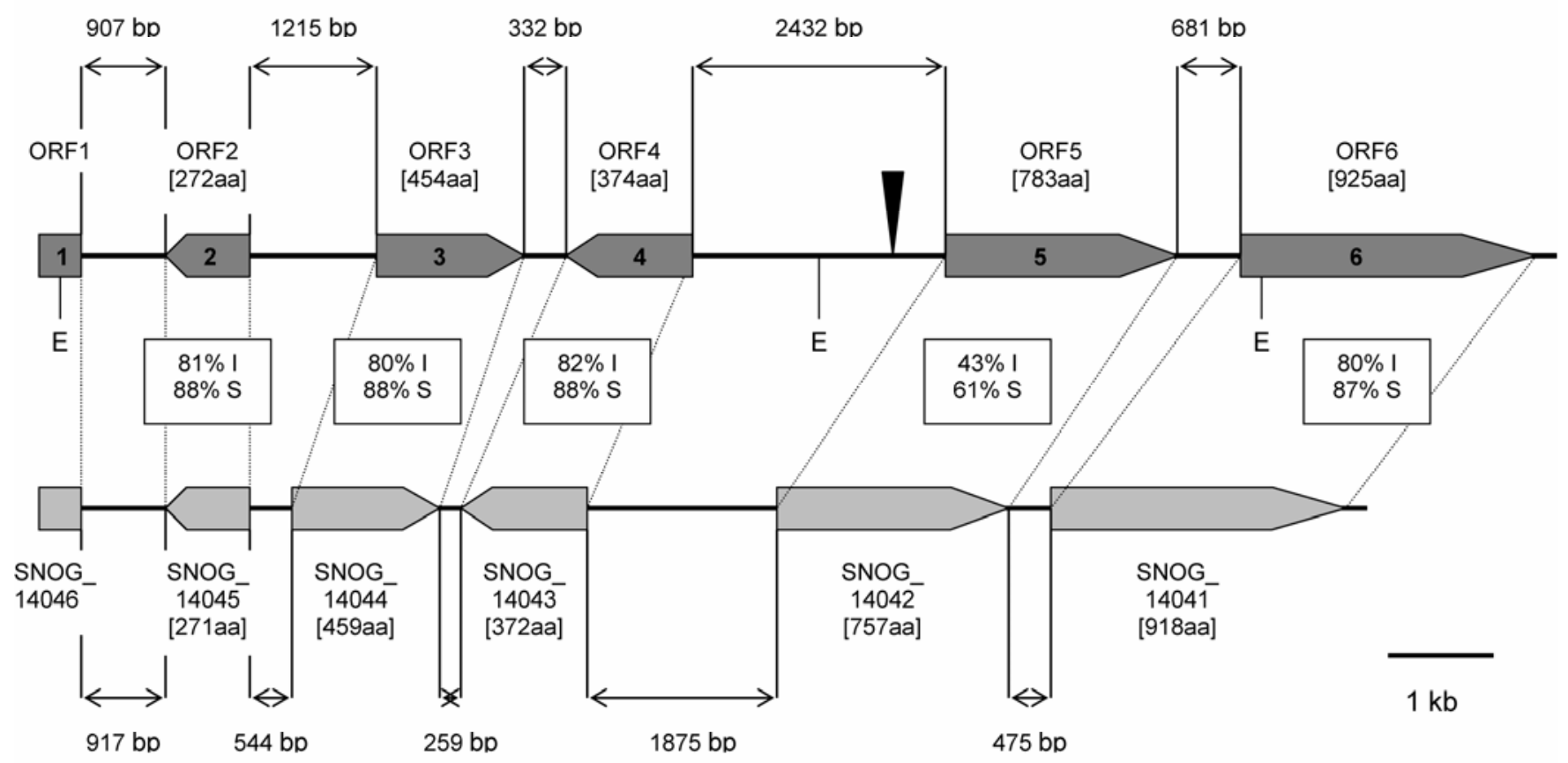

\section{S. nodorum}

Fig. 2. Location of the T-DNA insertion in the genomic DNA of the Leptosphaeria maculans mutant m186 and conservation of synteny with the corresponding genomic region in Stagonospora nodorum. Genomic organization of the six L. maculans genes flanking the T-DNA insertion (indicated by a black arrowhead in the upper panel), was compared with that of its six $S$. nodorum orthologues (lower panel). Direction of transcription of each gene is indicated and number of amino acids (aa) of the corresponding predicted proteins are indicated between brackets. The percentage of identity (I) and similarity (S) between L. maculans and S. nodorum predicted proteins is mentioned. Intergenic distances with their corresponding number of base pairs (bp) are indicated. Orthologues and corresponding proteins between L. maculans and S. nodorum are connected by dotted lines. E = EcoRV site. 

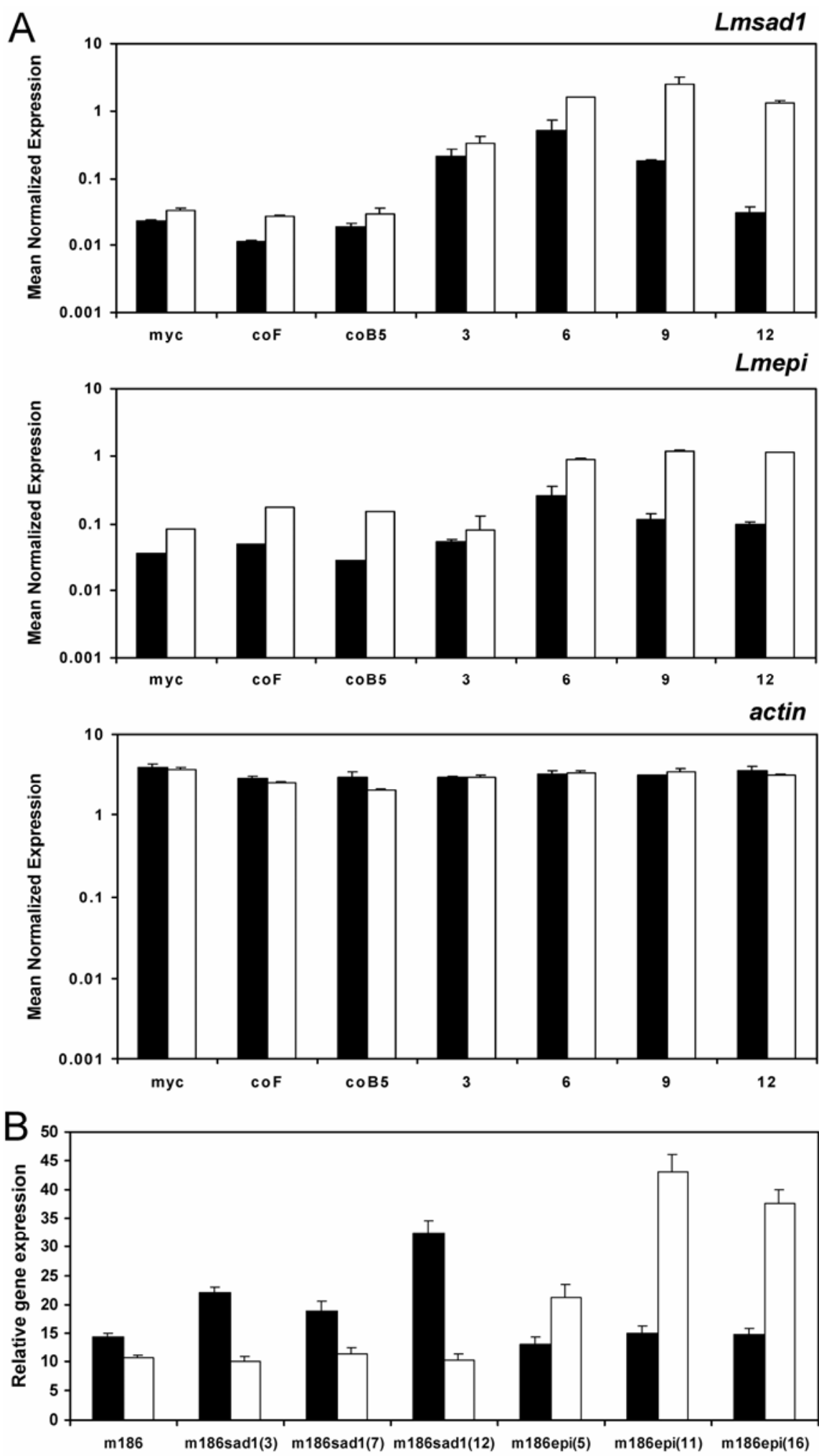

Fig. 3. Real-time polymerase chain reaction (PCR) comparison of Lmsadl and Lmepi expression in the Leptosphaeria maculans wild-type (WT), m186, and m186 complemented isolates during in vitro growth and infection of cotyledons of Brassica napus. A, Real-time PCR analysis of Lmsad1 and Lmepi expression in WT and $\mathrm{m} 186$ isolates. The following conditions were compared: myc, 3-week-old mycelial culture in Fries complete medium; co, 36-h-old conidia germinating in Fries complete medium (F) or under nitrogen starvation (B5); 3-12, oilseed rape cotyledons 3 to 12 days postinoculation. Gene expression levels are relative to $\beta$-tubulin expression. Actin is included to show that the calculated expression levels were not resulting from variations in the $\beta$-tubulin expression. Each data point is the average of two technical repeats and is representative of two biological repeats. Standard error of the mean normalized expression level is indicated by error bars. The WT and m186 isolates are displayed in black and white bars, respectively. B, Real-time PCR analysis of Lmsadl and Lmepi expression in $\mathrm{m} 186$ and $\mathrm{m} 186$ complemented isolates in oilseed rape cotyledons 9 days postinoculation. Gene expression levels are relative to $\beta$ tubulin expression and to the expression of the target gene in the WT isolate ( $2^{-\Delta \Delta \mathrm{Ct}}$ method). Each data point is the average of two technical repeats and is representative of two biological repeats. Standard error of the relative gene expression level is indicated by error bars. The Lmsadl and Lmepi genes are displayed in black and white bars, respectively. 
motif for the binding of the Gal4 transcriptional activator, 1,821 and 2,211 bp upstream of the start codon, respectively. Consistently with the presence of the latter, we found that expression of Lmepi was increased twofold in the WT isolate and threefold in $\mathrm{m} 186$ when galactose was the sole carbon source in the medium instead of glucose (Fig. 4B).
Mutant m186 is depleted in plant cell wall hydrolysis.

The structural interaction between plant cells and WT isolate or m186 hyphae was visualized by ultrastructural studies (Fig. 5). Samples of cotyledon tissue infected with the WT isolate showed a massive presence of the fungus even at $3 \mathrm{dpi}$, whereas m186 was present within the host cotyledon to a

Table 1. Pathogenicity behavior of the Leptosphaeria maculans wild-type (WT), m186, and m186 isolates complemented with candidate genes along with the entire intergenic sequence (m186sad1 and m186epi) on Brassica napus ${ }^{\mathrm{a}}$

\begin{tabular}{lccc}
\hline Pathogenicity & WT & m186 & m186sad1 \\
\hline On cotyledons $^{\mathrm{b}}$ & $4.5 \pm 0.4$ & $1.9 \pm 0.3(P=0.01)$ & $1.8 \pm 0.8(P=0.001)$ \\
On stems $^{\mathrm{c}}$ & 100 & 58 & $4.3 \pm 0.5(\mathrm{~ns})$ \\
Incidence $(\%)_{\text {Severity }(\mathrm{cm})}$ & $7.5 \pm 0.8$ & $5.9 \pm 1.3(P=0.05)$ & 93 \\
\hline
\end{tabular}

${ }^{\mathrm{a}}$ Data correspond to average values \pm standard deviation obtained after analysis of 14 and 15 complemented isolates of $\mathrm{m} 186 \mathrm{sad} 1$ and $\mathrm{m} 186 \mathrm{epi}$, respectively, and of three repeats for WT and m186 isolates. Student's test values were calculated between the WT isolate and m186, m186sad1, or $\mathrm{m} 186$ epi isolates. $P=$ probability and $\mathrm{ns}=$ not significant.

b Pathogenicity was assessed on cotyledons of B. napus cv. Westar at 17 days postinoculation. Data are mean disease ratings of approximately 10 inoculation sites scored according to the IMASCORE scale, where 1-3 represent resistance responses and 4-6 susceptibility symptoms.

${ }^{\mathrm{c}}$ Pathogenicity was assessed on stems of B. napus $\mathrm{cv}$. Westar 3 months after inoculation. Incidence $=$ percentage of plants with necrosis and severity $=$ mean length of expressed lesions.
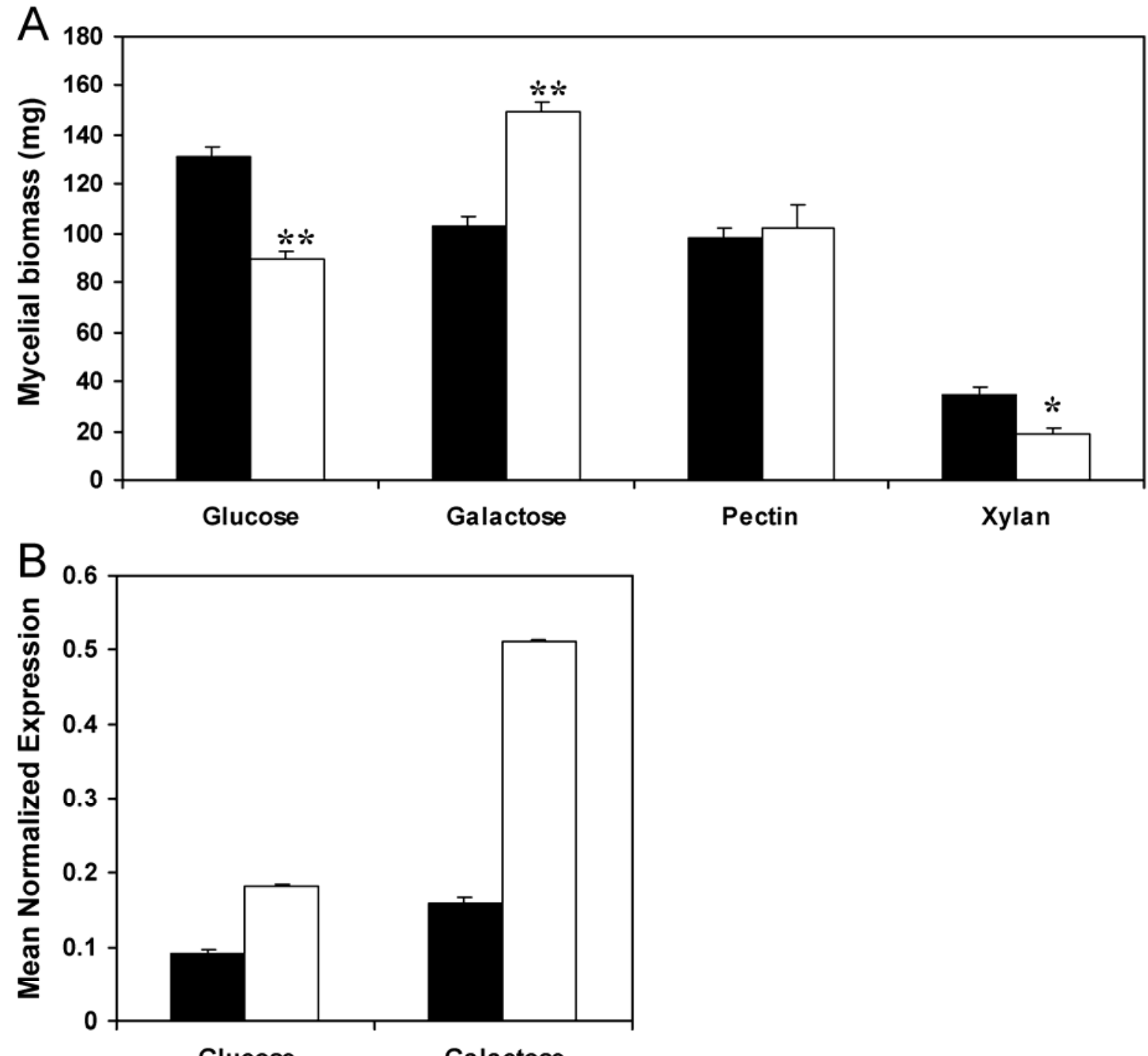

Glucose

Galactose

Fig. 4. Effect of carbon sources on growth and Lmepi expression in the Leptosphaeria maculans wild-type (WT) and m186 isolates. A, Growth and B, Lmepi expression were assessed in liquid Czapeck medium with either glucose, galactose (2 weeks after inoculation) (A and B), pectin, or xylan (A) (3 weeks after inoculation) as carbon sources. Data are average values \pm standard deviation of three technical repeats and are the mean of two biological repeats. WT and m186 isolates are displayed in black and white bars, respectively. Student's test values were calculated between the WT and m186 isolates. Probability * and ** indicate $P=0.05$ and 0.01 , respectively. 
much smaller extent. At 3 dpi, host cells were mostly well preserved and appeared still functional, as can be deduced from the well-preserved nucleus and chloroplasts. However, many plant cells in close contact with the WT isolate hyphae exhibited partly or completely degraded cell walls, whereas plant cells in close contact with the $\mathrm{m} 186$ hyphae displayed no signs of deterioration (Fig. 5A). This phenomenon was markedly increased at $14 \mathrm{dpi}$, where the WT isolate had killed most cells in the studied tissue, and invasion of dead host cells by hyphae of the WT isolate was regularly observed (Fig. 5B). In contrast, m186 had only a very limited negative effect on the viability of plant cells and caused almost no difference in host cell wall appearance even at 14 dpi. Invasion of host cells was never noted with m186 (Fig. 5B). Together, these observations indicated that m186 was unable to actively degrade the host cell wall and, thus, to switch to the necrotrophic lifestyle during the infection process.

We further investigated the ability of $\mathrm{m} 186$ to degrade the plant cell wall components. First, m186 was significantly affected in its capacity to grow on a complex sugar (i.e., xylan) as sole carbon source, whereas growth on pectin, another plant cell wall component, was not perturbed (Fig. 4A). In addition, m186 exhibited a significant reduction in the activity of at least two cell-wall-degrading enzymes (CWDE) when challenged with plant cell wall extract during in vitro growth (Fig. 6). Polygalacturonase activity was reduced in $\mathrm{m} 186$ by up to $20 \%$ compared with the WT isolate at 7 and 14 dpi, whereas xylanase activity was affected at 14 and 21 dpi by up to $30 \%$. In contrast, $\beta$-1,3-glucanase activity in m186 was similar to that of the WT isolate at all times examined (Fig. 6).

\section{DISCUSSION}

The Leloir pathway provides a unique means for eukaryotic cells to use galactose as a carbon and energy source by converting galactose to UDP-galactose and glucose-1-phosphate, the latter being then metabolized through glycolysis and the tricarboxylic acid cycle. UDP-glucose-4-epimerase is one of the four key enzymes of the Leloir pathway and catalyzes the final step in galactose metabolism by regenerating UDP-glucose from UDP-galactose (Holden et al. 2003). Here, we have shown that the Lmepi gene, which encodes a putative UDPglucose-4-epimerase, is involved in the pathogenicity of $L$. maculans toward Brassica napus. To our knowledge, this study

Table 2. Effect of cell-wall-perturbating agents on the radial growth of the Leptosphaeria maculans wild-type (WT) and m186 isolates ${ }^{\mathrm{a}}$

\begin{tabular}{lccl}
\hline Agents $^{\mathbf{b}}$ & WT & m186 & Student test $^{\mathbf{c}}$ \\
\hline MMII & $4.03 \pm 0.15$ & $4.30 \pm 0.10$ & $t=2.13(\mathrm{~ns})$ \\
Congo red $(0.25 \mathrm{mM})$ & $3.08 \pm 0.16$ & $2.23 \pm 0.15$ & $t=5.48(P=0.01)$ \\
SDS $(0.035 \mathrm{mM})$ & $3.33 \pm 0.21$ & $2.60 \pm 0.10$ & $t=4.45(P=0.05)$ \\
\hline
\end{tabular}

${ }^{\text {a }}$ Data are average values \pm standard deviation of three technical repeats and are representative of two biological repeats.

${ }^{\mathrm{b}}$ MMII = minimal medium II and SDS = sodium dodecyl sulfate .

${ }^{\mathrm{c}}$ Student's test values were calculated between the WT and $\mathrm{m} 186$ isolates. $P=$ probability and $\mathrm{ns}=$ not significant.
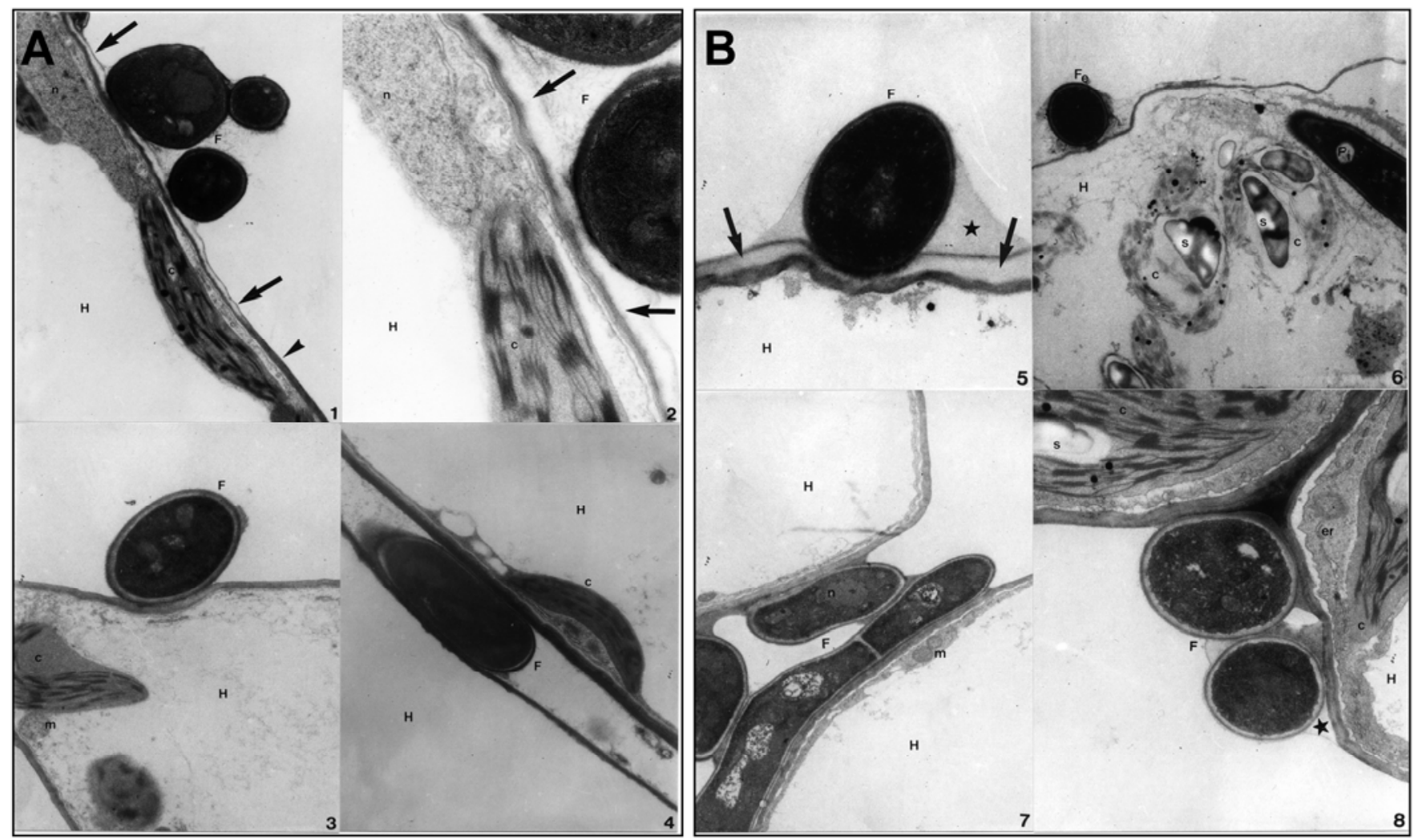

Fig. 5. Ultrastructural studies of infected plant material. Cotyledons infected with the Leptosphaeria maculans wild-type (WT) (1 and 2, 5 and 6$)$ and m186 ( 3 and 4,7 and 8) isolates. Photographs were taken at $\mathbf{A}, 3$ and $\mathbf{B}, 14$ days postinoculation. Arrows point to the almost completely degraded host cell wall at area of contact with the fungus, arrowhead to unaltered host cell wall areas, and asterisk to amorphous material apparently secreted by the fungus to facilitate adhesion. Magnification: $\times 7.040$ (1, 6, and 7), $\times 11.200$ ( 3 and 4), $\times 19.200$ (5 and 8), and $\times 32.000$ (2). Abbreviations: $\mathrm{c}=$ chloroplast, er $=$ endoplasmic reticulum, $\mathrm{F}=$ fungus, $\mathrm{Fe}=$ external hyphae, $\mathrm{Fi}=$ internal hyphae, $\mathrm{H}=$ host cell, $\mathrm{m}=$ mitochondrion, $\mathrm{n}=$ nucleus, and $\mathrm{s}=$ starch. 
is the first report concerning the implication of galactose metabolism in virulence of a plant-pathogenic fungus.

Sequence comparisons of LmEPI with UDP-glucose-4-epimerases of various eukaryotes revealed a high degree of homology among these proteins and strong conservation of residues involved in epimerization activity, which is consistent with the well-documented conservation of the Leloir pathway from yeast to human (Frey 1996). Indeed, a whole-genome search in L. maculans only revealed the presence of Lmepi as a potential UDP-glucose-4-epimerase-encoding gene, and also revealed the presence of unique putative homologues for gall and gal7, encoding two other key enzymes of this pathway, and for gal2, encoding a specific galactose permease (Martchenko et al. 2007). Functional and expression studies performed here included biological analysis of the effect of deregulation of expression, as well as analysis of the effect of biochemical agents known to interact with cell wall integrity. Growth improvement of m186 on galactose as sole carbon source was correlated with in vitro overexpression of Lmepi and was consistent with its putative involvement in galactose metabolism. Furthermore, galactose led to significantly increased Lmepi expression, consistently with the induction of the Leloir pathway genes by galactose in fungi (Martchenko et al. 2007). In Saccharomyces cerevisiae, the Leloir pathway genes are positively regulated by Gal4p, a zinc-finger protein acting through the upstream activator sequence $\left(\mathrm{UAS}_{\mathrm{Gal}}\right)$, whose occurrence in the Lmepi promoter region is also predicted. The higher sensitivity to Congo Red and SDS displayed by $\mathrm{m} 186$ also suggests that its cell wall integrity is affected, as was observed for the UDP-glucose-4-epimerase mutants of Schizosaccharomyces pombe and Candida albicans (Singh et al. 2007). Taken together, all these data suggest that Lmepi encodes for a functional UDP-glucose-4-epimerase, involved in galactose metabolism. However, an irrefutable demonstration of the function of LmEPI as an UDP-glucose-4-epimerase would be the successful heterologous complementation by the Lmepi gene of the corresponding mutant in Saccharomyces cerevisiae or measurement of the enzymatic activity of the purified protein.

Pathogenicity defect in m186 was associated with a threefold overexpression of the Lmepi gene in planta. This study is the third report of a T-DNA insertion leading to in planta overexpression of a pathogenicity gene in a phytopathogenic fungi, all of them relating to L. maculans (Elliott and Howlett 2006; Remy et al. 2008a). Moreover, T-DNA insertion in m186 occurred in a promoter region, as was the case for all $L$. maculans agrotransformants affected in their pathogenicity examined to date (Elliott and Howlett 2006; Remy et al. 2008a and b). A bias toward insertion of T-DNA into promoter regions has already been proposed for other models. In Cryptococcus neoformans, 10 of 14 pathogenicity tagged mutants generated by ATMT exhibited a T-DNA insertion into promoter regions (Walton et al. 2005). Such a bias was also observed in Arabidopsis thaliana (Pan et al. 2005), and could reflect T-DNA preference for highly transcribed genomic regions, where the chromatin structure is more relaxed. This bias is of particular interest, because it only leads to slight modification of gene expression rather than to complete inactivation, thus allowing assessment of the role of lethal genes in pathogenicity (Remy et al. 2008a and b). We found here that, although m186 overexpressed Lmepi, complementation of the mutant isolate with the Lmepi gene under the control of its entire natural promoter restores pathogenicity, as previously observed for the Lmgpil5 mutant but not the THIOL mutant of L. maculans (Elliott and Howlett 2006; Remy et al. 2008b). Moreover, complementation results in an increased Lmepi expression, at least in the three complemented isolates examined, thus suggesting that overexpression of Lmepi by itself is not responsible for the mutant phenotype. On these bases, we postulate that the TDNA insertion modifies or suppresses some regulatory elements present in the promoter region that are required for the correct regulation of Lmepi expression and, thus, that a fine regulation of Lmepi expression is required for a successful and complete infection of the host plant.

The sevenfold induction of Lmepi expression observed at the beginning of the cotyledon infection further suggests a special need for activating galactose metabolism during the first stages of tissue colonization. Cytological analysis indicated that m186 is not disturbed during the first step of the infectious process (i.e., germination on the plant surface and penetration of host tissues) or during the final step (i.e., sporulation) but is specifically impaired during the invasive growth phase. Thus, the lack of effect on the penetration phase in m186 could reflect catabolism of storage carbohydrates, as is usually shown in other phytopathogenic fungi (Divon and Fluhr 2007;

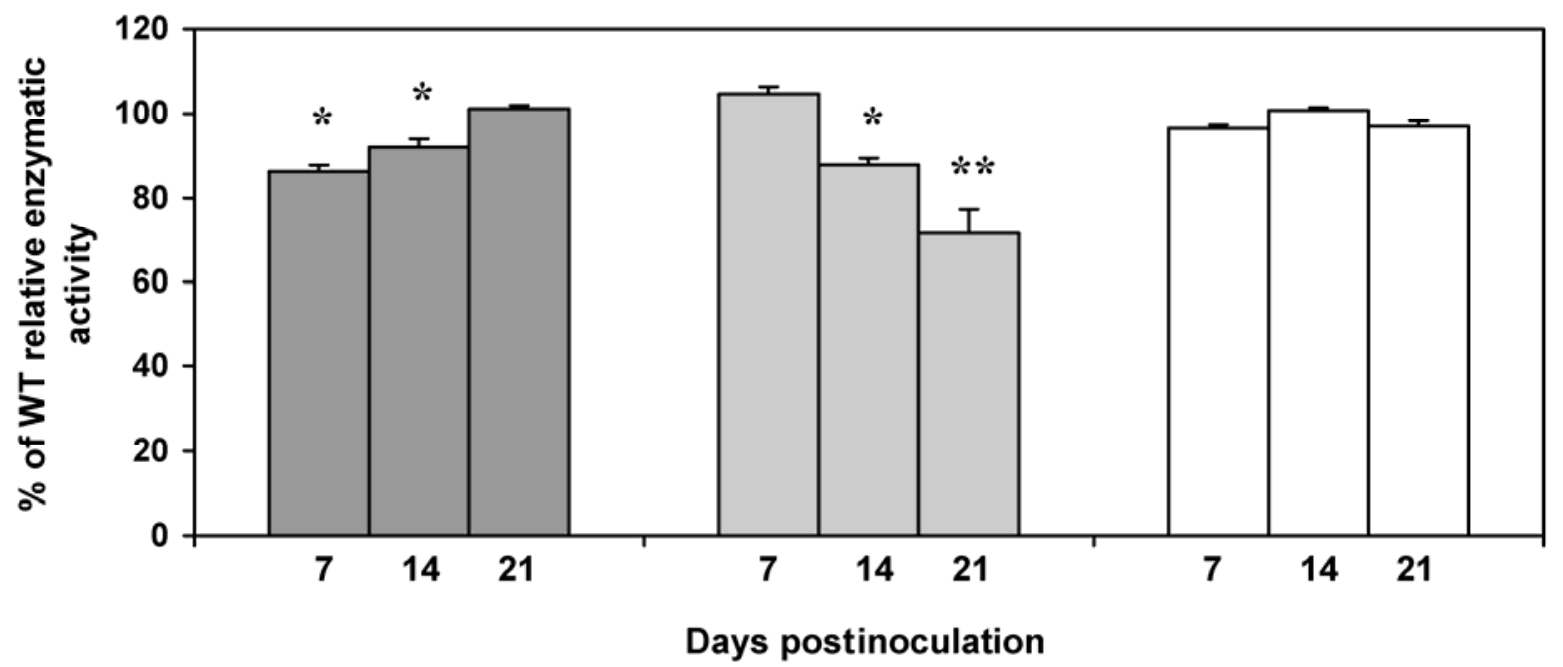

Fig. 6. Analysis of the cell-wall-degrading enzyme (CWDE) activities produced in vitro by the Leptosphaeria maculans m186 isolate. Three different CWDE activities were assessed with the m186 isolate grown for 7, 14, and 21 days in liquid synthetic Czapeck medium supplemented with oilseed rape cell walls as sole carbon source and compared with those produced by the wild-type (WT) isolate. Each datapoint is the average of two technical repeats and is representative of two biological repeats. Standard error of the percentage of WT activity is indicated by error bars. Polygalacturonase, xylanase, and $\beta$-1,3glucanase activities are displayed in dark gray, light gray, and white bars, respectively. For each enzymatic activity, significance of the differences between the WT and m186 isolates was evaluated with a Student's test. Probability: * and ** indicate $P=0.01$ and 0.001 , respectively. 
Solomon et al. 2003). At a latter stage of the colonization process, ultrastructural studies showed that m186 is totally unable to invade and kill plant cells or even deteriorate their walls, in contrast to the WT isolate, which completely degrades the plant cell wall and penetrates into host cells. Several CWDE activities have been detected in planta during infection of plant tissues by L. maculans, in particular at the time where lesions are spreading and hyphae are invading host cells (Annis and Goodwin 1997; Easton and Rossall 1985; Sexton et al. 2000). Although not validated by mutagenesis, these CWDE are thought to play a crucial role during colonization of host tissues (Annis and Goodwin 1997). Thus, the results obtained suggest that m186 is impaired in CWDE activity or secretion, therefore resulting in a reduced ability to switch between biotrophy and necrotrophy.

On these bases, we propose two distinct but nonexclusive hypotheses to explain the nonpathogenic behavior of $\mathrm{m} 186$. First, perception of nutrient availability in the external environment governs expression of CWDE-encoding genes via the carbon catabolic repression (CCR). This general process implies that, as long as sufficient amounts of a favorable nutrient source (i.e., glucose) are available, transcription of alternative uptake systems and catabolic enzymes is repressed (Divon and Fluhr 2007). In particular, once glucose has been completely exhausted, the CCR of CWDE is abolished and depolymerization of the plant cell wall provides the fungus with multiple carbon sources (Opsina-Giraldo et al. 2003; Tonukari et al. 2000). Because m186 is less able to use glucose than the WT isolate and does not seem to be able to degrade the plant cell walls, one possibility is that $\mathrm{m} 186$ is not able to completely deplete the plant apoplasm of glucose so that the synthesis of CWDE is permanently repressed. At this stage, as the fungal biomass increases, more nutrients are required to support growth, but m186 could be unable to cope with this feeding request, so that fungal growth stops. In accordance with this hypothesis, we observed the occurrence of a predicted site for the binding of the Mig1 factor in the Lmepi promoter. This site is located upstream of the T-DNA insertion, which could block the action of Mig1 on Lmepi expression. In Saccharomyces cerevisiae, Mig1 is a DNA-binding transcriptional repressor whose phosphorylation by the SNF1 protein kinase causes its dissociation from the promoter of glucose catabolic-repressed genes (Gancedo 1998). Mutants of SNF1 orthologues in Cochliobolus carbonum and Fusarium oxysporum were also compromised for growth on secondary carbon sources and for production of several secreted CWDE and, subsequently, exhibited a reduction in pathogenicity (Opsina-Giraldo et al. 2003; Tonukari et al. 2000). Another possible explanation for the m186 pathogenicity defect results from its loss of cell wall integrity. In Schizosaccharomyces pombe and Candida albicans, the role of Gal10p is not limited only to the metabolism of exogenous galactose but is also involved in cell wall integrity, even in the absence of galactose (Singh et al. 2007). In fact, UDP-glucose4-epimerase is the only Leloir pathway enzyme that plays a role in cell-wall biosynthesis in yeasts (Huang and Snider 1995; Singh et al. 2007). In the absence of galactose, it was postulated that UDP-glucose-4-epimerase provides the cell with UDP-galactose, essential for processes such as glycosylation of cell-wall proteins (Singh et al. 2007). In fact, galactose comprises approximately $30 \%$ of the mass of glucoprotein glycans in Schizosaccharomyces pombe (Huang and Snider 1995) and has also been detected in glycoproteins of Aspergillus fumigatus as well as of the Ascochyta pea complex (Bernard and Latgé 2001; Mendes-Pereira et al. 1999). Even if the cell wall composition of L. maculans is unknown at the moment, the higher sensitivity of m186 to cell-wall-damaging agents could be consistent with a change in glycosylation pattern of its cell wall glycoproteins. An overactive UDPglucose-4-epimerase would be expected to decrease the pool of UDP-galactose available for galactose-linked glycoproteins. The cell wall alteration of m186 would, in turn, result in limited colonization of host tissues as the fungal cell wall became more sensitive to lytic activity of antifungal plant compounds.

The role of lipid metabolism during fungal pathogenesis has received great attention in past years, in contrast to the carbohydrate one. Here, we suggest that galactose catabolism is tightly regulated during the infection process of L. maculans and that the slightest change in this regulation pathway can have profound effects on the pathogenicity of the fungus. Except for the sirodesmin toxin cluster, the intracellular $\mathrm{pH}$ homeostasis, and the GPI anchor biosynthesis pathway (Elliott et al. 2007; Remy et al. 2008a and b), all of the pathogenicity determinants uncovered to date in L. maculans are key components of primary metabolism, as is the case for the present study. Consequently, we postulate that precise adjustments of the primary metabolic pathways are crucial during infectionrelated development of $L$. maculans, which does not require specialized infection and feeding structures, such as appressoria or haustoria, but whose infection and tissue colonization strategies rely on colonization of plant apoplast and, thus, on the use of the nutrient sources available in intercellular spaces. Similarly, in the closely related Dothideomycete $S$. nodorum, showing infection strategies resembling those of L. maculans, all but three of the pathogenicity factors known so far are involved in primary metabolism, the three remaining factors belonging to signaling pathways (Bailey et al. 2000; Cooley et al. 1999; Solomon et al. 2004a and b, 2005a and b, 2006a and b). Compared with extensively studied Sordariomycetes infection strategies, relying on more diverse factors in link primarily with infection structure differentiation, this study highlights specificities of the Dothideomycetes, for which there is a need for continuous feeding within plant tissues for completing their life cycle and for which, mainly in the case of $L$. maculans, leaf symptoms only are the initial symptom prior to a very long endophytic growth within plant tissues.

\section{MATERIALS AND METHODS}

\section{Fungal isolates.}

The v23.1.3 isolate of L. maculans (Balesdent et al. 2002) was used as the recipient isolate for the generation of the ATMT collection of L. maculans (Blaise et al. 2007). In vitro crosses and random ascospore progeny recovery were performed as previously established (Gall et al. 1994). Two transformants, m186GFPa and m186GFPb, exhibiting a mutant phenotype and strongly expressing the GFP were isolated in the progeny of a cross between $\mathrm{m} 186$ and the near-isogenic isolate v41.4.6 (fifth backcross) of v23.1.3 isolate transformed by a GFP strongly expressing construct (Remy et al. 2008b). All fungal cultures were maintained on V8 juice agar medium and highly sporulating cultures were obtained on V8 juice medium as previously described (Ansan-Melayah et al. 1995).

\section{Pathogenicity and growth assays.}

Pathogenicity of isolates was first assessed following inoculation of cotyledons of cv. Westar, a highly susceptible genotype of B. napus, as previously described (Balesdent et al. 2001). Plants were incubated in a growth chamber at $18^{\circ} \mathrm{C}$ (night) and $24^{\circ} \mathrm{C}$ (day) with a 12-h photoperiod. Symptoms were scored 14, 17, and 21 dpi according to the semiquantitative IMASCORE rating scale, where scores up to 3 correspond to resistance responses of the plants and scores above 3 correspond to susceptibility (Balesdent et al. 2001). The ability to cause stem necrosis at later stages was evaluated by depositing 
a $10-\mu$ droplet of a $10^{7} \mathrm{ml}^{-1}$ suspension of conidia at the basis of the petiole of the second leaf of 1-month-old plantlets of cv. Westar wounded three times with a needle (Hammond and Lewis 1986). Incubation took place in the same conditions as for the cotyledon inoculation test. Twelve plants were inoculated per isolate and symptoms were scored 3 months postinoculation by numbering plants exhibiting lesion (incidence) and by measuring length of the necrosis whenever present (severity).

Growth was evaluated by inoculating $10^{8}$ conidia in $150 \mathrm{ml}$ of liquid Czapeck medium (Acea and Carballas 1990) in Roux bottles with either $87 \mathrm{mM}$ glucose or galactose, or $2 \%$ pectin or xylan as sole carbon source. Flasks were incubated at $22^{\circ} \mathrm{C}$ without shaking and mycelium was collected by vacuum filtration after 2 weeks for glucose and galactose and after 3 weeks for pectin and xylan. Dry mycelium biomass was weighed following freeze drying. In order to evaluate the sensitivity of isolates to reagents that affect cell wall integrity, radial growth tests were performed by depositing $10 \mu \mathrm{l}$ of water containing $10^{5}$ conidia in the center of $90-\mathrm{mm}$ petri dishes containing minimal medium II (MMII) (Pontecorvo et al. 1953) supplemented with either SDS or Congo red (Sigma-Aldrich, St. Louis) and by measuring the radial growth after a 2-week incubation at $22^{\circ} \mathrm{C}$. The range of concentrations assessed in each case was such that it never induced more than $30 \%$ inhibitory effect on the WT control.

\section{Nucleic acid manipulation, DNA sequencing, and real-time RT-PCR analysis.}

Genomic DNA used for PCR experiments was extracted from conidia using the DNeasy 96 plant kit (Qiagen S.A., Courtaboeuf, France) as described previously (Balesdent et al. 1998). Procedures for PCR and gel electrophoresis were adapted from procedures described by Sambrook and associates (1989). For cloning experiments, Nucleospin extract II, Nucleobond BAC 100, and Nucleospin Plasmid extraction kits (Macherey-Nagel, Hoerdt, France) were used for plasmid extractions, BAC extractions, and purification of DNA from agarose gels, respectively. Enzymatic digestions and ligations were performed according to the manufacturer's instructions (Invitrogen, Cergy Pontoise, France and New England Biolabs, Hitchin, U.K.). For cloning, Escherichia coli DH10B electrocompetent cells were prepared as described by Sambrook and associates (1989) and electroporated at $1.5 \mathrm{kV}$ and $50 \mu \mathrm{F}$.

For the rescue of genomic regions flanking the inserted TDNA, we used the TAIL-PCR method described by Blaise and associates (2007). The sequence flanking the left border of the T-DNA was recovered as a 383-bp fragment. Subsequently, a pair of specific primers (m186pan7F [5' TGGCCGGGTTGG ACT] and m186pan7R [5' TTCACTTCACTCGATCGACC]) was designed for PCR screening of the HindIII BAC library available in the laboratory (Gout et al. 2006). One positive BAC was digested with EcoRV and subcloned into pUC18 vector. Two inserts of 3,989 and 7,816 bp were sequenced by use of the GPS-Mutagenesis System (New England Biolabs, Hitchin, U.K.), providing us with a sequence of $11,805 \mathrm{bp}$ encompassing the T-DNA integration site. Sequencing was performed using a Beckman Coulter CEQ 8000 automated sequencer (Beckman Coulter, Fullerton, CA, U.S.A.) according to the manufacturer's instructions.

Quantitative RT-PCR was performed as previously described (Fudal et al. 2007). Total RNA was extracted from i) mycelium grown during 3 weeks in liquid Fries medium, ii) mycelium grown during 2 weeks in liquid Czapeck medium, iii) germinating conidia grown for $36 \mathrm{~h}$ in liquid Fries or B5 minimal medium, and iv) infected plants by using TRIzol reagent (Invitrogen). Extracts were treated with DNAseI (New England
Biolabs) according to the manufacturer's instructions. Total RNA $(5 \mu \mathrm{g})$ was reverse transcribed using an oligo-dT anchor and PowerScript Reverse Transcriptase (Clontech, Palo Alto, CA, U.S.A.). Oligonucleotides actF (5' AGTGCGATGTCGAT GTCAG) and actR (5' AAGAGCGGTGATTTCCTTCT) were used as primers to detect cDNAs corresponding to actin. Similarly, oligonucleotides tubF (5' AAGAACTCATCCTACT TCGT) and tubR (5' TGAATAGCTCCTGAATGG) were used for $\beta$-tubulin, Lmsad1F (5' TCACTGTGTCGCTCGCACTG) and Lmsad1R (5' AGTAGGATTTGACGGGTTTT) were used for Lmsad1, and LmepiF (5' AGTAGGTCAGGGGGATTTCA) and LmepiR (5' AAGCGACCCTCCTTTTACCA) were used for Lmepi. Cycle threshold $(\mathrm{Ct})$ values were analyzed as described by Muller and associates (2002) for expression kinetic analysis or according to the $2^{-\Delta \Delta \mathrm{Ct}}$ method (Livak and Schmittgen 2001) for complemented isolates.

\section{Bioinformatics analyses and gene annotation.}

Sequences were assembled using CAP3 available at the University of Lyon 1 website (Huang and Madan 1999) and the final genomic region was analyzed using FGENESH at the Softberry website (Salamov and Solovyev 2000) in order to search for potential ORF within the sequence. BLAST searches were performed at the National Center for Biotechnology Information website and at the Broad Institute website (Altschul et al. 1990). PFAM A at the Sanger Institute was used to search for conserved annotated domains (Sonnhammer et al. 1998). Promoter sequence was analyzed using the MatInspector algorithm at the Genomatix website (Cartharius et al. 2005). Multiple sequence alignment was realized using CLUSTALW at the European Bioinformatics Institute website (Thompson et al. 1994) and GeneDoc 2.6.002 (Nicholas and Nicholas 1997). Protein subcellular localization was predicted using WoLF PSORT (Horton et al. 2006).

Intron position was determined following PCR amplification and sequencing of the corresponding cDNA. Annotations of UTR and transcription start and stop sites were performed on cDNA using the Creator SMART cDNA Library Construction Kit (Clontech) according to the manufacturer's recommendations.

\section{Complementation experiments.}

For complementation experiment with Lmepi, the positive BAC clone selected (see below) was digested with PstI and HindIII, and the resulting 5.5-kb fragment was first introduced into the corresponding sites of pPZP201BK (a gift from Dr. Sarah Covert, University of Wisconsin, Madison, U.S.A.) (Covert et al. 2001). The insert was excised by use of HindIII and BamHI and introduced into the corresponding sites of pNAT1, which carries the nourseothricin acetyltransferase gene (NAT1) conferring resistance to the antibiotic nourseothricin (a gift from Dr. Barbara Howlett, University of Melbourne, Australia) (Gardiner et al. 2005). For the complementation experiment with Lmsad1, a 5-kb fragment was amplified by PCR using a specific primer pair (SadcompF [5' AGGCTGGGTGAGGTGGGCTTTGTGA] and SadcompR [5' TGGGTCAACGCATGACAGACAACGA]) and subcloned in TOPO-TA cloning vector. The insert was then excised by EcoRI and introduced into the EcoRI site of pNAT1.

The different constructs were then introduced into Agrobacterium tumefaciens strain C58pGV2260 by electroporation at $1.5 \mathrm{kV}, 200 \Omega$, and $25 \mu \mathrm{F}$. ATMT was performed as described by Gout and associates (2006). Transformants were selected on MMII medium supplemented with hygromycin B at 50 $\mu \mathrm{g} / \mathrm{ml}$ (Invitrogen) and nourseothricin at $50 \mu \mathrm{g} / \mathrm{ml}$ (Werner BioAgents, Jena, Germany), purified by single pycnidiospore isolation, and maintained on selective medium. 
Ultrastructural studies of infected cotyledons.

Chemical fixation for transmission electron microscopy. Samples with an area of approximately 1.5 by $3 \mathrm{~mm}$, including part of the inoculation wound, were cut with a razor blade from oilseed rape cv. Westar cotyledons infected with either WT isolate or m186 at both 3 and $14 \mathrm{dpi}$. They were placed into vials containing $2 \%$ glutaraldehyde in $0.1 \mathrm{M}$ cacodylate buffer ( $\mathrm{pH}$ 7.2) and infiltrated using a water jet pump for approximately $1 \mathrm{~min}$. Following six rinses in $0.1 \mathrm{M}$ cacodylate buffer, they were transferred to vials of secondary fixative consisting of $1 \% \mathrm{OsO}_{4}$ in cacodylate buffer for $2 \mathrm{~h}$ in the dark, washed in water, and stained en bloc with $1 \%$ aqueous uranyl acetate for $1 \mathrm{~h}$ in the dark. After five rinses with water, the material was dehydrated in acetone, with 10 -min changes at 25 , $50,70,95$, and $3 \times 100 \%$ anhydrous acetone. The samples were then placed into increasing concentrations of the ERL resin in acetone (1:2 for $30 \mathrm{~min}, 1: 1$ for $30 \mathrm{~min}, 2: 1$ overnight, pure ERL for $4 \mathrm{~h}$, and pure ERL overnight). All steps were performed at room temperature. Finally, samples were embedded in pure resin at $70^{\circ} \mathrm{C}$ for 1 day.

Cutting and poststaining of samples. Semithin sections of all treatments were made with a glass knife using an ultramicrotome (Ultracut Reichert-Jung, Vienna) and analyzed for the presence of fungal hyphae within the leaf with a light microscope. Ultrathin sections (60 to $90 \mathrm{~nm}$ ) were cut from wellpreserved samples showing the presence of such hyphae with a diamond knife (Diatome, Biel, Switzerland), placed onto copper grids coated with formavar, and poststained with $1 \%$ uranyl acetate in acetone for 20 min and Reynold's lead citrate for $20 \mathrm{~min}$. In between and after poststaining, sections were rinsed with distilled water. Finally, they were examined with a Zeiss EM 109 transmission electron microscope at $80 \mathrm{kV}$. At least 50 points of contact between hyphae of each fungal strain and host cells were analyzed both for 3- and 14-dpi samples.

\section{CWDE activity assays.}

In vitro culture was carried out by inoculating $10^{8}$ conidia in $100 \mathrm{ml}$ of liquid Czapeck medium supplemented with $1 \%$ (wt/vol) cell wall material prepared from greenhouse-grown 5week-old plants of oilseed rape cv. Westar, as described by Sposato and associates (1995). Aliquots from still cultures kept at $22^{\circ} \mathrm{C}$ were collected after 1,2 , and 3 weeks of growth and the endoglycosidase activities (xylanase, polygalacturonase, and $\beta$-1,3-glucanase) were assayed by the p-hydroxybenzoic acid hydrazide (PAHBAH) method (Lever 1972). Xylanase activity was measured using xylan (1\%,wt/vol) from oat spelts (Sigma-Aldrich) as substrate, polygalacturonase activity was determined using the polygalacturonic acid (1\% wt/vol) (Sigma-Aldrich) as a substrate, and laminarin $(1 \% \mathrm{wt} / \mathrm{vol})$ from Laminaria digitata (Sigma-Aldrich) was used as the substrate for $\beta$-1,3-glucanase activity. The reaction mixture of all endoglycosidase activity assays containing $50 \mathrm{mM}$ sodium acetate, $\mathrm{pH} 5.0$, was incubated at $37^{\circ} \mathrm{C}$ for $30 \mathrm{~min}$. At the end of the reaction, 25 or $100 \mu \mathrm{l}$ of the reaction mixture was added to $3 \mathrm{ml}(0.5 \% \mathrm{wt} / \mathrm{vol})$ of PAHBAH (Sigma-Aldrich) in $0.5 \mathrm{M}$ $\mathrm{NaOH}$. The samples were boiled at $100^{\circ} \mathrm{C}$ for $5 \mathrm{~min}$ and cooled to room temperature, and their absorbance was read at $410 \mathrm{~nm}$.

\section{ACKNOWLEDGMENTS}

This work was partly funded by Centre Technique des Oléagineux Métropolitains (CETIOM, Paris, France). E. Remy was funded by a fellowship from the French ministry of research. We thank E. MendesPereira and A. Gautier (INRA-BIOGER) for sequencing assistance; L. Coudard, M. Chabirand, J. P. Narcy, and J. Roux (INRA-BIOGER) for technical assistance; S. Covert (University of Wisconsin, U.S.A.) and B. J. Howlett (University of Melbourne, Australia) for pPZP201BK and pNAT1 plasmids, respectively; and Y. J. Huang (Rothamsted Research, U.K.) for GFP isolate.

\section{LITERATURE CITED}

Acea, M. J., and Carballas, T. 1990. Principal components analysis of the soil microbial population of humid zone of Galicia (Spain). Soil Biol. Biochem. 22:749-759.

Altschul, S.F., Gish, W., Miller, W., Myers, E.W., and Lipman, D.J. 1990. Basic local alignment search tool. J. Mol. Biol. 215:403-410.

Annis, L. S., and Goodwin, H. P. 1997. Production and regulation of polygalacturonase isozymes in Canadian isolates of Leptosphaeria maculans differing in virulence. Can. J. Plant Pathol. 19:358-365.

Ansan-Melayah, D., Balesdent, M. H., Buée, M., and Rouxel, T. 1995. Genetic characterization of AvrLm1, the first avirulence gene of Leptosphaeria maculans. Phytopathology 85:1525-1529.

Asakura, M., Okuno, T., and Takano, Y. 2006. Multiple contributions of peroxysomal metabolic function to fungal pathogenicity in Colletotrichum lagenarium. Appl. Environ. Microbiol. 72:6345-6354.

Bailey, A., Mueller, E., and Bowyer, P. 2000. Ornithine decarboxylase of Stagonospora (Septoria) nodorum is required for virulence toward wheat. J. Biol. Chem. 275:14242-14247.

Balesdent, M. H., Jedryczka, M., Jain, L., Mendes-Pereira, E., Bertrandy, J., and Rouxel, T. 1998. Conidia as a substrate for internal transcribed spacer-based PCR identification of members of the Leptosphaeria maculans species complex. Phytopathology 88:1210-1217.

Balesdent, M. H., Attard, A., Ansan-Melayah, D., Delourme, R., Renard, M., and Rouxel, T. 2001. Genetic control and host range of avirulence toward Brassica napus cultivars Quinta and Jet Neuf in Leptosphaeria maculans. Phytopathology 91:70-76.

Balesdent, M. H., Attard, A., Ansan-Melayah, D., Delourme, R., Renard, M., and Rouxel, T. 2002. New avirulence genes in the phytopathogenic fungus Leptosphaeria maculans. Phytopathology 92:1122-1133.

Bernard, M., and Latgé, J. P. 2001. Aspergillus fumigatus cell wall: Composition and biosynthesis. Med. Mycol. 39:9-17.

Blaise, F., Remy, E., Meyer, M., Zhou, L., Narcy, J. P., Roux, J, Balesdent, M. H., and Rouxel, T. 2007. A critical assessment of Agrobacterium tumefaciens-mediated transformation as a tool for pathogenicity gene discovery in the phytopathogenic fungus Leptosphaeria maculans. Fungal Genet. Biol. 44:123-138.

Cartharius, K., Frech, K., Grote, K., Haltmeier, M., Klingenhoff, A., Frisch, M., Bayerlein, M., and Werner, T. 2005. MatInspector and beyond: Promoter analysis based on transcription factor binding sites. Bioinformatics 21:2933-2942.

Cooley, R. N., Monk, T. P., McLoughlin, S. B., Foster, S. G., and Dancer, J. E. 1999. Gene disruption and biochemical characterisation of 3-isopropylmalate dehydrogenase from Stagonospora nodorum. Pestic. Sci. 55:364-367.

Covert, S. F., Kapoor, P., Lee, M., Briley, A., and Nairn, C. J. 2001. Agrobacterium-mediated transformation of Fusarium circinatum. Mycol. Res. 105:259-264.

Divon, H. H., and Fluhr, R. 2007. Nutrition acquisition strategies during fungal infection of plants. FEMS (Fed. Eur. Microbiol. Soc.) Microbiol. Lett. 266:65-74.

Easton, C. J., and Rossall, S. 1985. The production of certain cell wall-degrading enzymes by Leptosphaeria maculans in culture and in stem canker lesions of oilseed rape. Physiol. Plant Pathol. 26:185-197.

Elliott, C. E., and Howlett, B. J. 2006. Overexpression of a 3-ketoacylCoA thiolase in Leptosphaeria maculans causes reduced pathogenicity on Brassica napus. Mol. Plant-Microbe Interact. 19:588-596.

Elliott, C. E., Gardiner, D. M., Thomas, G., Cozijnsen, A., Van de Wouw, A., and Howlett, B. J. 2007. Production of the toxin sirodesmin PL by Leptosphaeria maculans during infection of Brassica napus. Mol. Plant Pathol. 8:791-802.

Frey, P. A. 1996. The Leloir pathway: A mechanistic imperative for three enzymes to change the stereochemical configuration of a single carbon in galactose. FASEB (Fed. Am. Soc. Exp. Biol.) J. 10:461-470.

Fudal, I., Ross, S., Gout, L., Blaise, F., Kuhn, M. L., Eckert, M. R., Cattolico, L., Bernard-Samain, S., Balesdent, M. H., and Rouxel, T. 2007. Heterochromatin-like regions as ecological niches for avirulence genes in the Leptosphaeria maculans genome: Map-based cloning of AvrLm6. Mol. Plant-Microbe Interact. 20:459-470.

Gall, C., Balesdent, M. H., Robin, P., and Rouxel, T. 1994. Tetrad analysis of acid phosphatase, soluble protein patterns, and mating type in Leptosphaeria maculans. Phytopathology 84:1299-1305.

Gancedo, J. M. 1998. Yeast carbon catabolite repression. Microbiol. Mol. Biol. Rev. 62:334-361.

Gardiner, D. M., Jarvis, R. S., and Howlett, B. J. 2005. The ABC transporter gene in the sirodesmin biosynthetic gene cluster of Leptosphae- 
ria maculans is not essential for sirodesmin production but facilitates self-protection. Fungal Genet. Biol. 42:257-263.

Gout, L., Fudal, I., Kuhn, M. L., Blaise, F., Eckert, M., Cattolico, L., Balesdent, M. H., and Rouxel, T. 2006. Lost in the middle of nowhere: The AvrLm1 avirulence gene of the Dothideomycete Leptosphaeria maculans. Mol. Microbiol. 60:67-80.

Gupta, A., and Chattoo, B. B. 2007. A novel gene MGA1 is required for appressorium formation in Magnaporthe grisea. Fungal Genet. Biol. 44:1157-1169.

Hagan, I., and Yanagida, M. 1995. The product of the spindle formation gene sad1+ associates with the fission yeast spindle pole body and is essential for viability. J. Cell Biol. 129:1033-1047.

Hammond, K. E., and Lewis, B. G. 1986. Ultrastructural studies of the limitation of lesions caused by Leptosphaeria maculans in stems of Brassica napus var. oleifera. Physiol. Mol. Plant Pathol. 28:251-265.

Holden, H. M., Rayment, I., and Thoden, J. B. 2003. Structure and function of enzymes of the Leloir pathway for galactose metabolism. J. Biol. Chem. 278:43885-43388.

Horton, P., Park, K. J., Obayashi, T., and Nakai, K. 2006. Protein subcellular localization Prediction with WoLF PSORT. Pages 39-48 in: Proceedings of the 4th Annual Pacific Bioinformatics Conference APBC06, Taipei, Taiwan.

Huang, H. M., and Snider, M. D. 1995. Isolation of protein glycosylation mutants in the fission yeast Schizosaccharomyces pombe. Mol. Biol. Cell. 6:485-496.

Huang, X., and Madan, A. 1999. CAP3: A cDNA sequence assembly program. Genome Res. 9:868-877.

Idnurm, A., and Howlett, B. J. 2002. Isocitrate lyase is essential for pathogenicity of the fungus Leptosphaeria maculans to canola (Brassica napus). Eukaryot. Cell 1:719-724.

Klose, J., and Kronstad, J. W. 2006. The multifunctional beta-oxidation enzyme is required for full symptom development by the biotrophic maize pathogen Ustilago maydis. Eukaryot. Cell 5:2047-2061.

Kyte, J., and Doolittle, R. F. 1982. A simple method for displaying the hydropathic character of a protein. J. Mol. Biol. 157:105-132.

Lever, M. 1972. A new reaction for colorimetric determination of carbohydrates. Anal. Biochem. 47:273-279.

Livak, K. J., and Schmittgen, T. D. 2001. Analysis of relative gene expression data using real-time quantitative PCR and the $2^{-\Delta \Delta \mathrm{Ct}}$ method. Methods 25:402-408.

Martchenko, M., Levitin, A., Hogues, H., Nantel, A., and Whiteway, M. 2007. Transcriptional rewiring of fungal galactose-metabolism circuitry. Curr. Biol. 17:1-7.

Mendes-Pereira, E., Faris-Mokaiesh, S., Bertrandy, J., and Spire, D. 1999. Characterisation of the mycelial glycoproteins of the 'Ascochyta pea complex' (Ascochyta pisi Lib., Mycosphaerella pinodes (Berk. And Blox.) and Phoma medicaginis var. pinodella (Jones) Boerema). Agronomie 19:21-29.

Muller, P. Y., Janovjak, H., Miserez, A. R., and Dobbie, Z. 2002. Processing of gene expression data generated by quantitative real-time RTPCR. Biotechniques 32:1372-1378.

Odenbach, D., Breth, B., Thines, E., Weber, R. W., Anke, H., and Foster, A. J. 2007. The transcription factor Con7p is a central regulator of infection-related morphogenesis in the rice blast fungus Magnaporthe grisea. Mol. Microbiol. 64:293-307.

Opsina-Giraldo, M. D., Mullins, E., and Kang, S. 2003. Loss of function of the Fusarium oxysporum SNF1 gene reduces virulence on cabbage and Arabidopsis. Curr. Genet. 44:49-57.

Pan, X., Li, Y., and Stein, L. 2005. Site preferences of insertional mutagenesis agents in Arabidopsis. Plant Physiol. 137:168-175.

Perfect, E. S., and Green, J. R. 2001. Infection structures of biotrophic and hemibiotrophic fungal plant pathogens. Mol. Plant Pathol. 2:101-108.

Pontecorvo, G., Roper, J. A., Hemmons, L. M., MacDonald, K. D., and Bufton, A. W. 1953. The genetics of Aspergillus nidulans. Adv. Genet. 5:141-238.

Ramos-Pamplona, M., and Nagvi, N. I. 2006. Host invasion during riceblast disease requires carnitine-dependent transport of peroxysomal acetyl-CoA. Mol. Microbiol. 61:61-75.

Remy, E., Meyer, M., Blaise, F., Chabirand, M., Wolff, N., Balesdent, M. H., and Rouxel, T. 2008a. The Lmpmal gene of Leptosphaeria maculans encodes a plasma membrane $\mathrm{H}^{+}$-ATPase isoform essential for pathogenicity towards oilseed rape. Fungal Genet. Biol. 45:11221134.
Remy, E., Meyer, M., Blaise, F., Simon, U. K., Kuhn, D., Chabirand, M Riquelme, M., Balesdent, M. H., and Rouxel, T. 2008b. The Lmgpi15 gene, encoding a component of the glycosylphosphatidylinositol anchor biosynthesis pathway, is required for morphogenesis and pathogenicity in Leptosphaeria maculans. New Phytol. 179:1105-1120.

Rouxel, T., and Balesdent, M. H. 2005. The stem canker (blackleg) fungus, Leptosphaeria maculans, enters the genomic era. Mol. Plant Pathol. 6:225-241.

Salamov, A. A., and Solovyev, V. V. 2000. Ab initio gene finding in Drosophila genomic DNA. Genome Res. 10:516-522.

Sambrook, J., Fritsch, E. F., and Maniatis, T. 1989. Molecular Cloning: A Laboratory Manual, 2nd ed. Cold Spring Harbor Laboratory Press, Cold Spring Harbor, NY, U.S.A.

Sexton, A. C., Paulsen, M., Woestemeyer, J., and Howlett, B. J. 2000. Cloning, characterization and chromosomal location of three genes encoding host cell-wall degrading enzymes in Leptosphaeria maculans, a fungal pathogen of Brassica spp. Gene 248:89-97.

Singh, V., Satheesh, S. V., Raghavendra, M. L., and Sadhale, P. P. 2007. The key enzyme in galactose metabolism, UDP-galactose-4-epimerase, affects cell-wall integrity and morphology in Candida albicans even in the absence of galactose. Fungal Genet. Biol. 44:563-574.

Solomon, P. S., Tan, K. C., and Oliver, R. P. 2003. The nutrient supply of phytopathogenic fungi: A fertile field for study. Mol. Plant Pathol. 4:203-210.

Solomon, P. S., Lee, R. C., Wilson, T. J., and Oliver, R. P. 2004a. Pathogenicity of Stagonospora nodorum requires malate synthase. $\mathrm{Mol}$. $\mathrm{Mi}$ crobiol. 53:1065-1073.

Solomon, P. S., Tan, K. C., Sanchez, P., Cooper, R. M., and Oliver, R. P. $2004 \mathrm{~b}$. The disruption of a G $\alpha$ subunit sheds new light on the pathogenicity of Stagonospora nodorum on wheat. Mol. Plant-Microbe Interact. 17:456-466.

Solomon, P. S., Tan, K. C., and Oliver, R. P. 2005a. Mannitol 1-phosphate metabolism is required for sporulation in planta of the wheat pathogen Stagonospora nodorum. Mol. Plant-Microbe Interact. 18:110-115.

Solomon, P. S., Waters, O. D., Simmonds, J., Cooper, R. M., and Oliver, R. P. 2005b. The Mak2 kinase signal transduction pathway is required for pathogenicity in Stagonospora nodorum. Curr. Genet. 48:60-68.

Solomon, P. S., Jorgens, C. I., and Oliver, R. P. 2006a. Delta-aminolaevulinic acid synthesis is required for virulence of the wheat pathogen Stagonospora nodorum. Microbiology 152:1533-1538.

Solomon, P. S., Rybak, K., Trengove, R. D., and Oliver, R. P. 2006b. Investigating the role of calcium/calmodulin-dependent protein kinases in Stagonospora nodorum. Mol. Microbiol. 62:367-381.

Sonnhammer, E. L. L., Eddy, S. R., Birney, S. R., Bateman, A., and Durbin, R. 1998. Pfam: Multiple sequence alignments and HMM-profiles of protein domains. Nucleic Acids Res. 26:320-322.

Sposato, P., Ahn, J. H., and Walton, J. D. 1995. Characterization and disruption of a gene in the maize pathogen Cochliobolus carbonum encoding a cellulase lacking a cellulose binding domain and hinge region. Mol. Plant-Microbe Interact. 8:602-609.

Thines, E., Weber, R. W. S., and Talbot, N. J. 2000. MAP kinase and protein kinase A-dependent mobilization of triacylglycerol and glycogen during appressorium turgor generation by Magnaporthe grisea. Plant Cell 12:1703-1718.

Thompson, J. D., Higgins, D. G, and Gibson, T. J. 1994. CLUSTAL W: Improving the sensitivity of progressive multiple sequence alignment through sequence weighting, position-specific gap penalties and weight matrix choice. Nucleic Acids Res. 22:4673-4680.

Tonukari, N. J., Scott-Craig, J. S., and Walton, J. D. 2000. The Cochliobolus carbonum SNF1 gene is required for cell-wall degrading enzyme expression and virulence on maize. Plant Cell 12:237-247.

Walton, F. J., Idnurm, A., and Heitman, J. 2005. Novel gene functions required for melanization of the human pathogen Cryptococcus neoformans. Mol. Microbiol. 57:1381-1396.

Wang, Z. Y., Thornton, C. R., Kershaw, M. J., Debao, L., and Talbot, N. J. 2003. The glyoxylate cycle is required for temporal regulation of virulence by the plant pathogenic fungus Magnaporthe grisea. Mol. Microbiol. 47:1601-1612.

\section{AUTHOR-RECOMMENDED INTERNET RESOURCE}

Genedoc homepage: www.nrbsc.org/gfx/genedoc 